\section{CAPACIDADES DINÂMICAS EM UM AMBIENTE DE CRISE: UMA ANÁLISE COMPARATIVA DE CASOS DO SETOR DE VAREJO DE VESTUÁRIO E CALÇADOS}

Objetivo do trabalho: explorar evidências sobre a relevância das capacidades dinâmicas para o desempenho econômico das empresas e sobre o papel mediador do ambiente externo na relação capacidade-desempenho no contexto da crise políticoeconômica brasileira do período 2015-2017.

Metodologia: estudo comparativo de dois casos de empresas familiares de mesmos setor e idade, mas com resultados econômicos opostos. Questionário estruturado e entrevista semiestruturada foram aplicados a um conselheiro de administração.

Originalidade: discute-se dinâmica ambiental e capacidades como elementos fundamentais ao desempenho. Enquanto a primeira tem sido pouco discutida no campo da estratégia, as últimas são ainda pouco exploradas em contextos de crise.

Principais resultados: demonstrou-se a complexidade envolvida em pesquisas que relacionam ambiente, capacidades e desempenho. A relevância das capacidades dinâmicas foi evidenciada, mas a governança corporativa foi demonstrada como elemento fundamental para o desenvolvimento de tais capacidades. A ideia de tolerância ambiental é levantada diante de empresas longevas que não desenvolveram algumas capacidades estratégicas ao longo dos anos.

Contribuições teóricas: retoma-se a relevância do ambiente externo nos estudos de estratégia e propõe-se a governança corporativa como uma capacidade fundamental a ser investigada no contexto das capacidades dinâmicas. $\mathrm{O}$ fator temporal entre capacidades e desempenho é também destacado. Dependência da trajetória e capacidades ordinárias são sugeridas como elementos importantes para a construção de uma teoria baseada em capacidades.

Palavras-chave: Capacidades Dinâmicas. Dinâmica Ambiental. Desempenho. Crise. Análise Comparativa.
Renata Barcelos

Doutora em Administração pela Universidade Federal de Minas Gerais - UFMG. Brasil. E-mail: renatabarcel@yahoo.com.br

Daniel Paulino Teixeira Lopes Doutor em Administração pelo Centro de PósGraduação e Pesquisas em Administração da Universidade Federal de Minas Gerais (CEPEAD/UFMG). Professor do Centro Federal de Educação Tecnológica de Minas Gerais - CEFET-MG. Brasil.E-mail:daniel.lopes@globo.com

Carlos Alberto Gonçalves

Doutor em Administração pela Universidade de São Paulo - USP. Professor da Universidade Federal de Minas Gerais - UFMG e da Fundação Mineira de Cultura, Universidade FUMEC. Brasil. E-mail: calberto@fumec.br

Allan Claudius Queiroz Barbosa

Doutor em Administração pela Universidade de São Paulo - USP. Professor da Universidade Federal de Minas Gerais - UFMG. Brasil. E-mail: allan@ufmg.br

Recebido em: 16 de janeiro, 2018

Aprovado em: 08 de maio, 2018

Processo de Avaliação: Double Blind Review 


\section{DYNAMIC CAPACITIES IN A CRISIS ENVIRONMENT: A COMPARATIVE ANALYSIS OF CASES FROM THE RETAIL AND CLOTHING RETAIL SECTOR}

Objective: Our objective was to explore evidence of the relevance of dynamic capabilities to the economic performance of companies and on the mediating role of the external environment in the relation between capabilities and performance in the context of the Brazilian political-economic crisis of 2015-2017.

Methodology: This was a comparative study of two cases of family companies of the same sector and stage, which have demonstrated opposite economic results. Structured questionnaires and semi-structured interviews were applied to a board member from each company.

Originality: Environmental dynamics and capabilities are discussed as fundamental elements to performance. The former has been discussed little in the field of strategy and the latter has been explored little in crisis contexts.

Main results: We demonstrated the complexity involved in research relating environment, capacities, and performance. The relevance of dynamic capabilities was evidenced, but corporate governance was demonstrated to be a fundamental element for the development of such capabilities. The idea of environmental tolerance is raised in the face of long-term companies that have not developed some strategic capabilities over the years.

Theoretical contributions: The relevance of the external environment is highlighted in the studies of strategy. Furthermore, corporate governance is proposed as a fundamental area to be investigated in the context of dynamic capacities. The time factor between capabilities and performance is also highlighted. Path dependence and ordinary capacities are suggested as important elements for building a theory based on capabilities.

Keywords: Dynamic Capabilities. Environmental Dynamics. Performance. Crisis. Comparative Analysis.

\section{CAPACIDADES DINÁMICAS EN UN AMBIENTE DE CRISIS: UN ANÁLISIS COMPARATIVO DE CASOS DEL SECTOR DE VENTAS AL POR MENOR DE VESTUARIO Y CALZADOS}

Objetivo del trabajo: explorar evidencias sobre la relevancia de las capacidades dinámicas para el desempeño económico de las empresas y sobre el papel mediador del ambiente externo en relación a la capacidad y desempeño en el contexto de la crisis político-económica brasileña del período 2015-2017.

Metodología: estudio comparativo de dos casos de empresas familiares del mismo sector y edad, pero con resultados económicos opuestos. El cuestionario estructurado y la entrevista semiestructurada se aplicaron a un consejero de administración.

Originalidad: se discute la dinámica ambiental y las capacidades como elementos fundamentales al desempeño. Mientras que la primera ha sido poco discutida en el campo de la estrategia, las últimas son todavía poco exploradas en contextos de crisis.

Principales resultados: se demostró la complejidad involucrada en investigaciones que relacionan el ambiente, las capacidades y el rendimiento. La relevancia de las capacidades dinámicas fue evidenciada, pero la gobernanza corporativa fue demostrada como elemento fundamental para el desarrollo de tales capacidades. La idea de tolerancia ambiental se plantea ante empresas antiguas que no han desarrollado algunas capacidades estratégicas a lo largo de los años.

Contribuciones teóricas: se retoma la relevancia del ambiente externo en los estudios de estrategia y se propone la gobernanza corporativa como una capacidad fundamental a ser investigada en el contexto de las capacidades dinámicas. El factor temporal entre capacidades y rendimiento es también destacado. La dependencia de la trayectoria y las capacidades ordinarias se sugieren como elementos importantes para la construcción de una teoría basada en capacidades.

Palabras clave: Capacidades Dinámicas. Dinámica Ambiental. Desempeño. Crisis. Análisis Comparativo. 


\section{INTRODUÇÃO}

O conceito das capacidades dinâmicas trabalhado por Collis (1994) e Teece, Pisano e Shuen (1997) trouxe a discussão das capacidades para um lugar de destaque (Peteraf, Di Stefano, \& Verona, 2013) e, recentemente, observam-se ensaios sobre uma visão (ou teoria) da firma baseada em capacidades (Leiblein, 2011; Teece, 2017).

Segundo o artigo seminal sobre o tema (Teece et al., 1997), capacidades dinâmicas seriam fundamentais para o bom desempenho das firmas em contextos de dinâmica ambiental causada pelas mudanças tecnológicas que marcam e aceleram a evolução dos sistemas econômicos.

A aceleração da dinâmica ambiental e o sucesso do construto fizeram com que as capacidades dinâmicas fossem consideradas importantes em quaisquer ambientes, independente de fatores essencialmente tecnológicos (Eisenhardt \& Martin, 2000). Uma larga discussão em torno do tema tem se estabelecido desde então, a despeito de linhas de argumentação concorrentes e do baixo nível de definição de alguns autores sobre as capacidades dinâmicas (Cepeda \& Vera, 2007).

Mesmo assim, o enfoque nas capacidades não propiciou que o tema da dinâmica ambiental avançasse nos campos teórico e empírico. Definida como a taxa de mudança e o grau de instabilidade do ambiente (Dess \& Beard, 1984), as bases teóricas sobre a dinâmica ambiental (ambiente externo à firma) ainda estão pautadas por estudos isolados ou antigos, localizados, principalmente, nas décadas de 1970 e 1980. Uma falha na evolução teórica parece ter surgido desde então, provavelmente pelo enfoque em recursos assumido pelo campo dos estudos estratégicos (Hoskisson, Hitt, Wan, \& Yiu, 1999).

Schilke (2014) demonstrou que pode haver uma correlação entre dinâmica ambiental e capacidades dinâmicas em forma de uma curva $U$ invertido: para ambientes pouco ou excessivamente dinâmicos, as capacidades dinâmicas perderiam a força para explicar o desempenho das empresas. Nesse sentido, é possível que a realidade brasileira no período de crise econômica e política (Pereira, Tanure, Teixeira, \& Missio, 2017), que se fortaleceu em 2015 e tem perdurado até 2017, seja condizente com o lado direito da curva proposta, o que significaria que, neste contexto, as capacidades dinâmicas perderiam importância.

Tal conclusão parece fazer sentido especial no Brasil, na medida em que os diversos solavancos vivenciados pelas empresas brasileiras ao longo de toda a sua história têm construído poucas organizações inovadoras e competitivas e o país continua com baixo destaque nos rankings de inovação mundiais (Cornell University, INSEAD, \& WIPO 2017). Assim, a pergunta que orienta o presente estudo é: diante do ambiente de crise vivenciado no Brasil no período 2015-2017, as capacidades dinâmicas tiveram importância na explicação do desempenho das empresas?

Ao realizar uma busca de artigos nas principais bases de periódicos em Administração (Web of Science, Scopus, Scielo, EBSCO e SPELL) sobre essa temática ${ }^{1}$, apenas dois estudos foram encontrados nessa linha (Fainshmidt, Nair, \& Mallon, 2017; Schilke, 2014), muito embora focados em grandes multinacionais, na realidade americana e nas capacidades de gestão de ativos durante a crise mundial de 2008 .

Tendo isso em vista, o objetivo deste artigo é buscar pistas sobre como as capacidades dinâmicas e a dinâmica ambiental estão relacionadas ao desempenho das empresas durante a crise vivenciada no Brasil no período 2015-2017. Para alcançá-lo, foi conduzido um estudo exploratório (Selltiz, Jahoda, Deutsch, \& Cook, 1967) que permitiu maior familiarização sobre a relevância de tais capacidades nos períodos de crise mais aguda nos anos de 2015 e 2016 (Carvalho, 2017), como as mesmas evoluíram no ano de 2017 e o impacto dessa realidade no desempenho de 2017, uma vez que a temporalidade entre a realização das capacidades dinâmicas e o impacto no resultado pode ser relevante (Zahra, Sapienza, \& Davidsson, 2006).

Por tratar-se de tema ainda pautado por indefinições e, principalmente, complexo, utilizouse de método qualitativo comparativo aplicado a duas empresas brasileiras de setores aproximados: uma delas no setor de vestuário e outra no setor de calçados, ambos pautados por dinâmica inerente aos eventos de moda e troca de coleções contínuas. Os mercados que ambas atendem são equivalentes: majoritariamente, classe C. Uma delas é classificada pelo informante como empresa de excelente resultado e outra como empresa de resultado muito ruim. $\mathrm{O}$ método utilizado foi de entrevista semiestruturada conjugada com questionário estruturado, seguindo recomendações de King, Keohane e Verba (1995), a fim de se ter uma mensuração objetiva e simétrica de cada um dos casos e dos construtos investigados.

\footnotetext{
${ }^{1}$ As palavras buscadas no Portal de Periódicos da CAPES foram "dynamic capabilities", "environment", "dynamic" e "crisis".
} 


\section{AS CAPACIDADES DINÂMICAS - DEFINIÇÕES E CORRELAÇÃO COM A DINÂMICA AMBIENTAL}

Originariamente, as capacidades dinâmicas (Teece et al., 1997) foram aplicadas a contextos de ambientes externos turbulentos a partir da visão baseada em recursos (Barney, 1991) e de bases na teoria evolucionária (Nelson \& Winter, 2005). Elas seriam uma base fundamental para a inovação e para a sobrevivência das empresas diante do mecanismo de seleção do mercado moldado por ambientes turbulentos marcados pela inovação tecnológica.

Eisenhardt e Martin (2000) contribuíram para uma localização mais ampla dessas capacidades na medida em que consideraram a velocidade dos mercados independentemente de características exclusivamente tecnológicas. Nessa abordagem, capacidades dinâmicas existem tanto em mercados mais estáveis quanto nos mais rápidos, mas apresentam características diferentes em cada um deles, o que abre um leque mais amplo para seu estudo.

Diante de um construto que explica como se defender e tirar melhor proveito dessas realidades, as capacidades dinâmicas ganharam espaço nos estudos acadêmicos, mesmo com as críticas ao construto como sendo tautológico e mal delimitado (Karna, Richter, \& Riesenkampff, 2016).

Capacidades dinâmicas podem ser de três tipos (Teece, 2014): (1) perceptivas (as quais permitem que a empresa perceba oportunidades e ameaças do ambiente na qual ela está inserida), (2) capacidades de apreensão (as quais permitem que a empresa decida e priorize sobre oportunidades e ações a serem adotadas) e (3) capacidades de reconfiguração (permitem que a firma reconfigure seus recursos e suas capacidades por meio da inovação).

Estudos empíricos recentes tentaram demonstrar a correlação entre as capacidades dinâmicas e o desempenho em ambientes dinâmicos (Karna et al., 2016; Schilke, 2014). As conclusões salientam a importância das capacidades dinâmicas para o desempenho, mas com outras considerações relevantes. Schilke (2014), por exemplo, conclui que as capacidades dinâmicas estão mais fortemente correlacionadas à vantagem competitiva em ambientes moderadamente dinâmicos. Uma curva em U invertido é proposta para esquematizar que em ambientes mais estáveis ou turbulentos, elas não poderiam estar associadas ao bom desempenho das firmas.

Fainshmidt, Nair e Mallon (2017) enfatizam que a eficácia das capacidades dinâmicas pode ser moldada pela forma como as empresas interagem com seu ambiente próximo (clientes, fornecedores e competidores) ao longo do tempo. Já os resultados de Karna, Richter e Riesenkampff (2016) sugerem que, mesmo em ambientes dinâmicos, as capacidades dinâmicas possuem tanta relevância quanto capacidades ordinárias para explicar o desempenho, propondo uma visão mais moderada às teorias que consideram as capacidades dinâmicas como superiores às ordinárias nesse tipo de cenário.

Zahrae Sapienza e Davidsson (2006) esclarecem que os efeitos positivos das capacidades dinâmicas - os quais não são obrigatórios e podem sequer existir - requerem tempo para se mostrarem em função dos custos envolvidos no desenvolvimento e exercício das capacidades dinâmicas. Tal ideia é fundamental para se medir correlações entre capacidades dinâmicas e desempenho e também foi adotada por Fainshmidt, Nair e Mallon (2017).

Entretanto, os estudos supracitados ainda deixam ambiguidade e dúvidas conceituais acerca do tema da dinâmica ambiental e, considerando tal gap da literatura, o tópico seguinte discute a dinâmica ambiental em maior nível de profundidade.

\section{A DINÂMICA AMBIENTAL}

Mesmo tendo sido originalmente situadas em um mundo schumpeteriano de competição baseada na inovação, rivalidade de preço e performance, retornos crescentes e destruição criativa de competências existentes (Teece et al., 1997), o conceito das capacidades dinâmicas já se expandiu para outros tipos de ambientes, tais como os ambientes ambíguos e imprevisíveis (Eisenhardt, Furr, \& Bingham, 2010) ou ambientes de crise (Fainshmidt et al., 2017; Makkonen, Pohjola, Olkkonen, \& Koponen, 2014).

O campo da prática administrativa tem levantado a importância da temática da dinâmica ambiental ao destacarem abordagens do tipo: "você não pode fazer investimentos inteligentes na sua organização a menos que compreenda como o setor está mudando" (McGahan, 2004). A recente perspectiva de um mundo volátil, incerto, complexo e ambíguo (VUCA - volatile, uncertain, complex, ambiguous) (Bennett \& Lemoine, 2014) está alinhada a essa visão e considera possibilidades de mudanças mais significativas e impactantes.

Entretanto, a dinâmica ambiental é tratada no artigo seminal de Teece, Pisano e Shuen (1997) com baixo nível de rigor teórico ou ontológico. Introduzida originalmente como "regimes of rapid 
change" (p. 509), até hoje não está claro nos estudos principais das capacidades dinâmicas a definição formal de tal dinamismo nem formas adequadas de medição, deixando para o leitor a escolha de, por exemplo, considerar o nível de dinamismo como oriundo ou da intensidade ou da velocidade das mudanças.

Romme, Zollo e Berends (2010), por exemplo, tratam a dinâmica ambiental como mudanças no mercado e nas tecnologias, sem maiores detalhamentos. Becker e Knudsen (2005) e Parnell, Long e Lester (2015) somam a incerteza a essa dinâmica e Rueda-Manzanares e Arago (2008) consideram, além da incerteza, a complexidade. Já Eisenhardt, Furr e Bingham (2010) esclarecem as múltiplas dimensões do dinamismo ambiental e somam aos fatores acima a ambiguidade e imprevisibilidade

A despeito de sua relevância, estudos que se aprofundam no tema e medição de tal construto se baseiam em propostas bastante antigas e concentradas principalmente na década de 1980 (Jansen, Bosch, \& Volberda, 2006; Li \& Liu, 2014). Essa realidade demonstra como o tema evoluiu pouco ao longo dos últimos anos, possivelmente devido à dominância na área de estratégia, pelo menos em termos teóricos, da visão baseada em recursos (Hoskisson et al., 1999).

Daft, Sormuren e Parks (1988) auxiliam nessa discussão propondo elementos a serem avaliados pelos executivos de grandes empresas no momento da análise ambiental e um dos autores mais citados é Duncan (1972), o qual explicita elementos relativos ao ambiente externo para explicar as fontes de incerteza ambiental a partir de 5 componentes: clientes, fornecedores, concorrentes, tecnologias e componente sóciopolítica.

De acordo com Eisenhardt e Martin (2000), mercados moderadamente dinâmicos são aqueles nos quais mudanças ocorrem frequentemente, mas seguem trajetórias previsíveis e lineares. Eles possuem estrutura setorial relativamente estável, com fronteiras bem definidas e competidores, clientes e outros envolvidos são bem conhecidos. Já nos mercados muito dinâmicos, mudanças ocorrem de forma não linear e são menos previsíveis. Neles, as fronteiras de mercado são dificilmente definidas, modelos de negócio são pouco claros e os atores (clientes, fornecedores, competidores etc.) são ambíguos e com papéis que se alteram. Enfim, os autores definem um ambiente dinâmico como aquele no qual inovações tecnológicas, competição globalizada e ação empreendedora atuam em uma frequência ampliada.
Se as questões de definição ainda se encontram duvidosas, problemas de medição do construto são inevitáveis. Fainshmidt, Nair e Mallon (2017) concluem, a partir de suas tentativas de medição, que o dinamismo ambiental é construto multifacetado e multinível. Mesmo tendo seguido literatura já estabelecida para definir e operacionalizar tais construtos, os autores reconhecem a natureza imperfeita de tais medidas na captura de sua complexidade e recomendam que pesquisadores busquem aproximações mais holísticas para se examinar o ambiente.

\section{DESEMPENHO DA FIRMA E RELAÇÃO COM AS CAPACIDADES DINÂMICAS E O AMBIENTE}

O ambiente é tido como um moderador da relação entre capacidades e desempenho, ou seja, ele interfere na predição de uma função entre os dois construtos (Chan, Yee, Dai, \& Lim, 2016; Jansen et al., 2006; Sharma, Durand, \& Gur-Arie, 1986). Já a relação entre capacidades dinâmicas e desempenho é abordagem menos complexa e tratada por diversos estudos sobre o tema (Takahashi, Bulgacov, Semprebon, \& Giacomini, 2016; Alves, Barbieux, Reichert, Tello-Gamarra, \& Zawislak, 2017). Entretanto, o desafio sempre presente é a definição do tipo desempenho a ser investigado.

O construto do desempenho organizacional não tem uma definição universal ou amplamente aceita. Richard, Devinney, Yip, e Johnson (2009) esclarecem que sua definição é surpreendentemente ‘aberta', mesmo tratando-se do principal interesse dos estudos da gestão. Tal amplitude é relacionada aos diversos stakeholders interessados na firma, sendo que o modelo anglo saxão que privilegia os interesses dos acionistas tem sido a principal referência nos estudos de estratégia.

Outros fatores que geram dificuldade de delimitação do desempenho são a heterogeneidade - o desempenho pode ser percebido de formas diferentes dependendo do porte da empresa analisada - e a duração - uma vez que o desempenho pode ser ocasionado por eventos randômicos e a visão de curto, médio ou longo prazo muda as referências para que ele seja avaliado.

Denrell, Fang e Zhao (2013) demonstram que o desempenho superior sustentado ao longo do tempo pode ser um indicador menos confiável em realidades nas quais eventos de sorte (chance events) tenham consequências duradouras. Eles defendem que o desempenho superior sustentado 
pode resultar de acidentes históricos ("where certain actors happened to be at the right place at the right time" (p. 194)), especialmente em função de processos de vantagem estratégica cumulativa.

Richard et al. (2009) citam mais de 200 medidas de desempenho presentes em alguns dos principais periódicos do Management. Entretanto, as principais são referentes a medidas econômicas tais como: fluxo de caixa da operação, EBIT, EBITDA, participação no mercado, lucro líquido operacional, retorno sobre ativos, margem de lucro, vendas e crescimento de vendas, entre outras. Já Makkonen et al. (2014) defendem que o crescimento da receita é uma medida de desempenho mais aderente ao grau de ajuste da empresa ao ambiente externo e Protogerou, Caloghirou e Lioukas (2011) salientam a importância de medidas relativas ao setor para a avaliação do desempenho.

\section{MÉTODO}

O presente trabalho parte de uma ideia geral de que empresas com maiores níveis de capacidades dinâmicas possuem maiores chances de terem melhor desempenho em ambientes dinâmicos. Entretanto, devido a indefinições, complexidade dos eventos correlacionados e inexistência de um estudo como esse no Brasil em um período de crise, optou-se por uma abordagem qualitativo-descritiva que possibilitasse a exploração detalhada (Selltiz et al., 1967) dos eventos investigados.

O interesse em setores do varejo deveu-se especificamente pelo forte impacto sofrido durante o período de crise (Gasparini, 2016; Paula \& Pires, 2017). A fonte de informações foi a escolha mais crítica do estudo: uma vez que capacidades dinâmicas envolvem ações estratégicas, o entrevistado deveria atuar em posições que permitissem que ele pudesse ler tais capacidades e julgá-las de forma relativa a outras empresas e experiências. Diante disso, optou-se por buscar conselheiros de administração que pudessem participar da pesquisa.

Um evento fortuito possibilitou a construção da pesquisa com um viés comparativo: a identificação de um conselheiro de administração que conhecia em profundidade a realidade do período 2015-2017 vivenciada por duas empresas de resultados opostos. Tratou-se de uma oportunidade rara, pois, geralmente, profissionais com atuação estratégica não podem atuar em empresas de um mesmo setor. Nos casos analisados, a distância geográfica e a regionalidade dos mercados permitiu que um mesmo conselheiro atuasse nas duas empresas, por não haver concorrência entre elas ${ }^{2}$.

Os procedimentos metodológicos compreenderam 3 etapas: análise de dados secundários acerca do ambiente externo e do setor no qual as empresas se inseriam, aplicação de questionário e entrevista semiestruturada, nesta ordem.

A análise da realidade brasileira foi realizada previamente à entrevista para se verificar se os construtos teóricos de medição de dinâmica ambiental estariam adequados à realidade do contexto brasileiro. Uma análise de dados secundários da maior empresa de capital aberto do setor foi também realizada a fim de se confirmar os elementos relevantes ao setor.

Seguindo as orientações de King et al. (1995), foram adotadas técnicas estruturadas e semiestruturadas para a construção de dois estudos de caso comparativos com escolha intencional com o intuito de perceber nuances que pudessem fortalecer ou demonstrar fragilidades da aplicação das teorias das capacidades dinâmicas às realidades das empresas investigadas.

Ainda que não se tenha como objetivo desenvolver inferências causais, acredita-se que a descrição objetiva dos eventos investigados por meio de um questionário estruturado seja especialmente importante no caso do ambiente de crise brasileiro, uma vez que é inútil buscar explicação do que não se tem descrito com um grau razoável de precisão. Acredita-se que esse formato propicie melhoria da acurácia das análises dos elementos a serem descritos (King et al., 1995; Ragin, 2008).

Assim, na busca de equanimidade da avaliação do conselheiro sobre ambas as empresas, evitando que a participação do entrevistador pudesse alterar a percepção do respondente, o protocolo de pesquisa teve a seguinte sequência:

1 - contato inicial por telefone: o conselheiro indicou todas as empresas nas quais atuava e foi solicitado que ele indicasse se a empresa apresentava bom ou mal desempenho (deixando o

\footnotetext{
${ }^{2}$ Um inconveniente encontrado nessa escolha foi relativo ao tempo de atuação do conselheiro na empresa: enquanto na Empresa de Desempenho Superior, o conselheiro já atuava desde 2015, na Empresa de Desempenho Inferior, começou a atuar em janeiro de 2017. Entretanto, o conselheiro declarou que conhecia muito bem a realidade dessa última desde 2015, por ter se aproximado da empresa em 2016 e por tê-la analisado em profundidade antes de assumir a vaga no conselho de administração.
} 
critério de desempenho de forma ainda subjetiva). A partir da identificação de empresas de desempenhos opostos em setores aproximados, a entrevistadora solicitou que uma entrevista presencial fosse realizada. A entrevista foi marcada para o final de novembro de 2017, período no qual os resultados sobre o ano de 2017 já poderiam ser percebidos;

2 - contato presencial - etapa sem intervenção da entrevistadora: foi apresentado ao respondente um questionário estruturado elaborado no software LimeSurvey e solicitou-se que as perguntas fossem respondidas primeiramente para a empresa de desempenho superior e, posteriormente, para a empresa de desempenho inferior;

3 - contato presencial - etapa de entrevista semiestruturada: após o término do questionário, realizou-se entrevista visando compreender cada uma das empresas e seus contextos e buscando justificativa para as respostas ao questionário respondido.
Os casos foram estruturados textualmente a partir da entrevista semiestruturada. Os dados obtidos por meio do questionário estruturado foram organizados e, posteriormente, conciliados com os textos elaborados. Os resultados foram analisados com base em gráficos comparativos para facilitar a análise.

A análise comparativa permite identificar semelhanças e diferenças entre os casos, sendo que as primeiras permitem identificar pontos de relevância causal para o fenômeno de interesse, contribuindo para a explicação geral ao mesmo. Já as diferenças, permitem refinar a explicação geral do fenômeno de interesse (Balestro, Vargas, \& Machado, 2007; Giraud, 2009).

\section{Categorias de análise}

Para a elaboração do questionário estruturado, foram criadas e adaptadas escalas de medição dos três construtos em questão, uma vez que todos eles tratam de conceitos multidimensionais. O Quadro 1 esclarece todos os indicadores utilizados para a medição do nível de dinâmica ambiental percebido pelas empresas. Para cada um deles, foi solicitado que o respondente desse uma nota de 1 a 10 , sendo 1 igual a ambiente totalmente estável e 10 igual a ambiente totalmente turbulento.

\begin{tabular}{|l|cl|}
\hline Categoria analisada (Daft et al., 1988; Porter, 1986) & & \multicolumn{1}{c|}{ Elementos avaliados } \\
\hline Evolução tecnológica & • Percepção da força da inovação tecnológica \\
\hline Dinâmica dos fornecedores & $\bullet$ & Produtos substitutos \\
\hline Dinâmica dos clientes & $\bullet$ & Dinâmica do ambiente de fornecedores \\
\hline Dinâmica da concorrência & $\bullet$ & Nível de dinâmica do de clientes \\
\hline Dinâmica de regulação & - Novos entrantes \\
\hline Dinâmica do ambiente econômico & $\bullet$ & Nível de dinâmica do ambiente regulatório \\
\hline Dinâmica do ambiente político & $\bullet$ & Nível de dinâmica do ambiente econômico \\
\hline
\end{tabular}

Quadro 1 - Categorias analisadas para a descrição da dinâmica do ambiente externo Fonte: Elaborado pelos autores

Nota. Mesmo não estando presente em nenhuma escala de outros autores, o cenário político foi inserido por ter marcado fortemente a realidade brasileira no período 2015-2017. O uso do termo diretamente deveu-se à tentativa de aproximação de eventos políticos determinantes para as firmas e de isolamento de questões econômicas que derivam deles.
Com relação às capacidades dinâmicas, utilizou-se a tipologia de Teece (2014) detalhada nas categorias de Karna, Richter e Riesenkampff (2016) para se objetivar elementos a serem medidos (Quadro 2). Foi solicitado que o respondente marcasse sua resposta numa escala de 5 pontos para cada variável, sendo 1 igual a "péssima ou inexistente" e 5 igual à "excelente". 
Capacidades Dinâmicas em um Ambiente de Crise: Uma Análise Comparativa de Casos do Setor de Varejo de Vestuário e Calçados

\begin{tabular}{|c|c|c|}
\hline $\begin{array}{c}\text { Tipos de } \\
\text { capacidades } \\
\text { (Teece, 2014) }\end{array}$ & Categorias (Karna et al, 2016) & Elementos avaliados \\
\hline \multirow[t]{2}{*}{ Perceptivas } & $\begin{array}{l}\text { Cooperação, alianças e } \\
\text { relacionamentos externos }\end{array}$ & Cooperação ou parcerias com agentes externos \\
\hline & Pesquisa e Desenvolvimento & Pesquisa e desenvolvimento \\
\hline \multirow{4}{*}{$\begin{array}{l}\text { Decisivas e } \\
\text { capacidades de } \\
\text { apreensão }\end{array}$} & \multirow{4}{*}{$\begin{array}{l}\text { Capacidade de tomada de decisão } \\
\text { estratégica e pesquisa de mercado }\end{array}$} & Monitoramento ambiental \\
\hline & & Monitoramento do mercado cliente \\
\hline & & Agilidade na tomada de decisão estratégica \\
\hline & & Planejamento e controle estratégico \\
\hline \multirow{5}{*}{$\begin{array}{c}\text { Capacidades } \\
\text { de } \\
\text { reconfiguração }\end{array}$} & \multirow{4}{*}{ Capacidade de inovação } & Inovação em produto ou serviço \\
\hline & & Inovação gerencial e organizacional e administrativa \\
\hline & & Inovação em mercado \\
\hline & & Inovação em processos \\
\hline & Capacidade de financiamento & Capacidade de financiamento de inovação \\
\hline \multirow{3}{*}{$\begin{array}{c}\text { Outras } \\
\text { capacidades } \\
\text { dinâmicas }\end{array}$} & Gestão estratégica de RH & Gestão estratégica de RH \\
\hline & Gestão de conhecimento & Práticas estruturadas de gestão de conhecimento \\
\hline & Ativos intangíveis e reputação & Reputação da empresa \\
\hline
\end{tabular}

Quadro 2 - Categorias analisadas para a descrição de elementos de capacidades dinâmicas Fonte: Elaborado pelos autores

As questões foram repetidas para 2 períodos: 2015-2016 e 2017 com o objetivo de perceber variações nas capacidades em função da variação do nível de dinâmica ambiental e do tempo necessário para a implantação das capacidades dinâmicas, uma vez que a crise brasileira deu demonstrações de arrefecimento no ano de 2017 (Carvalho, 2017) e que as capacidades podem exigir tempo de maturação.

Já para as medidas de desempenho, o objetivo de se avaliar o desempenho mais finalístico das empresas trazia a opção de se medir tanto o crescimento da receita (Schilke, 2014) quanto uma medida de rentabilidade, tal como EBITDA. Entretanto, diante da amplitude do conceito, foi criado um indicador que permitisse que o próprio entrevistado escolhesse um critério de referência para cada uma das empresas, dando uma nota que variava de 1 a 10 (sendo $1=$ empresa com risco de falência e $10=$ empresa de crescimento rápido e sustentado). Partiu-se da premissa de que o termo "crescimento rápido" poderia remeter ao crescimento da receita, enquanto o termo "sustentado" poderia remeter a medidas econômicas. Durante a entrevista, o critério adotado pelo respondente foi investigado.

\section{APRESENTAÇÃO DOS CASOS ANALISADOS}

O ambiente externo das empresas de varejo no período de crise no Brasil
Instabilidades políticas e econômicas pautaram a realidade brasileira desde o ano de 2014, dentre elas, a queda do PIB, o impeachment da presidente Dilma Roussef ${ }^{3}$ e acusações de corrupção sobre o presidente Michel Temer até 2017 (Hermida \& Benites, 2017). Em dezembro de 2015, o país perdeu o grau de investimento pela agência de classificação de risco Fitch (Cleto \& Machado, 2015) e diversos indicadores oficiais demonstram a instalação de uma crise real, tais como o aumento do desemprego (Ramalho, 2017) e dos índices de incerteza do empresariado e do consumidor (Ferreira, 2017). O Produto Interno Bruto brasileiro sofreu quedas consecutivas ao longo de todo o triênio 2014-2016, passando por uma reversão no primeiro semestre de 2017 (Instituto Brasileiro de Geografia e Estatística [IBGE], 2018). Os dados de desemprego coletados pelo IBGE até o segundo trimestre de 2017 demonstravam início de melhoria a partir de abril de 2017 (IBGE, 2017).

No aspecto regulatório, alterações nas leis trabalhistas ocuparam a pauta, incluindo uma minirreforma trabalhista em 2016 (http://www.bbc.com/portuguese/salasocial38411553) e, em 2017, uma reforma trabalhista com mudanças mais profundas ${ }^{4}$.

\footnotetext{
${ }^{3}$ Conforme sentença constante no site do Senado Federal (https://www12.senado.leg.br/noticias/ arquivos/2016/08/31/veja-a-sentenca-de-impeachmentcontra-dilma-rousseff)

4 Lei 13.467, de julho de 2017 (http://www.planalto.gov.br/ccivil_03/_ato20152018/2017/lei/L13467.htm)
} 
O relatório anual 2016 da empresa Renner S.A. (Lojas Renner S.A., 2017) demonstrou que vários elementos do ambiente externo foram relevantes para a tomada de decisão estratégica, tais como, economia em recessão, crise política em âmbito nacional, pressões inflacionárias, aumento dos tributos que incidem sobre a folha de pagamentos, novas tecnologias e gerenciamento de riscos de questões legais na cadeia produtiva. Já no ano de 2017, a empresa divulgou que se planejou para um mercado mais sensível a preço (Alerigi, 2017).

\section{Apresentação das empresas}

A Empresa de Desempenho Inferior está situada no setor de varejo de calçados para as classes B, C e D, enquanto a Empresa de Desempenho Superior atua no setor de varejo de roupas e calçados para as classes C e D. Ambas possuem a mesma idade e um número de funcionários que faz com que sejam consideradas como empresas de grande porte: mais de 1.000 funcionários. O Quadro 3 ilustra as características das empresas.

\begin{tabular}{|c|c|c|}
\hline $\begin{array}{c}\text { COMPARATIVO DAS } \\
\text { EMPRESAS }\end{array}$ & $\begin{array}{c}\text { EMPRESA DE } \\
\text { DESEMPENHO INFERIOR }\end{array}$ & $\begin{array}{c}\text { EMPRESA DE } \\
\text { DESEMPENHO SUPERIOR }\end{array}$ \\
\hline Setor & Varejo de Vestuário/ Calçados & Varejo de Vestuário/ Calçados \\
\hline Região & Centro-Oeste do Brasil & Sudeste do Brasil \\
\hline Perfil de clientes & Classe C e D & Classe C e D \\
\hline Idade & 40 anos & 41 anos \\
\hline Número de funcionários & + de 1.000 funcionários & + de 1.000 funcionários \\
\hline Liderança de mercado & Sim & Não \\
\hline
\end{tabular}

Quadro 3 - Características das empresas comparadas

Fonte: a partir de entrevista semiestruturada

A presente seção segue primeiramente com a descrição dos casos para que o leitor possa contextualizar as duas empresas analisadas. Posteriormente, serão apresentados os resultados das respostas ao questionário estruturado, os quais evidenciam as semelhanças e diferenças entre elas.

\section{Caso 1: A empresa de Desempenho Inferior}

Trata-se de uma empresa do varejo calçadista que atua há 40 anos na região centrooeste brasileira. Vendendo principalmente para as classes B e C, tem larga variedade de produtos, chegando a atender inclusive a classe D. A nota de 1 a 10 para o desempenho geral da empresa foi 1 . Foi explicado ao conselheiro que o conceito de desempenho deveria se referir a uma visão geral e abrangente. Entretanto, na análise de desempenho por meio de outras métricas, a empresa apresentou durante todo o triênio 2015-2017 tanto o EBITDA quanto $\mathrm{O}$ crescimento da receita bruta significativamente melhores do que a média do mercado, o que foi explicado pelo conselheiro com a seguinte frase: "está ruim, mas está melhor do que muita gente".

A empresa tem o seu fundador como presidente, o qual conduziu a gestão de forma bastante pessoalizada e pouco profissionalizada. Em 2017, foi a primeira vez que a empresa passou por um processo de planejamento estratégico, após a instituição de um conselho de administração consultivo, o qual tem trabalhado para instalar maior racionalidade e profissionalismo.

Conforme informado pelo conselheiro independente, a empresa nunca teve um posicionamento claro no mercado e sempre vendeu produtos para classes sociais distintas. Seu presidente sente orgulho em dizer que se trata de uma empresa democrática, com produtos para todos os clientes que entram em sua loja.

Além da falta de foco para a elaboração de uma proposta de valor consistente para alguns segmentos de mercado, a empresa apresenta estoques muito elevados por ter que manter produtos muito variados e sujeitos à moda. Ela ainda pratica uma forma de cobrança arcaica: o carnê de cobrança, o qual foi bastante utilizado no Brasil nas décadas de 1970 e 1980.

Mesmo com essas características, a empresa cresceu por muitos anos. Durante a crise iniciada em 2014, ela começou a sofrer com a perda do poder aquisitivo dos clientes. A queda nas vendas impactou o EBITDA que passou a ser negativo no ano de 2017. Na mesma época, o presidente apresentou um problema de saúde e, por não ter sucessores formados, optou por instalar o conselho de administração. Neste primeiro ano, o conselho está construindo um projeto para mudanças significativas, mas o conselheiro entrevistado 
assume que elas não podem ocorrer rapidamente devido à cultura já instalada.

Segundo o conselheiro, em 2015 e 2016, as reuniões da empresa eram focadas no curto prazo e na gestão do caixa diário e, mesmo a partir da instalação do conselho, a empresa ainda não conseguiu enxergar um escopo de tempo para além de um ano para a tomada de decisão estratégica. Mesmo assim, a empresa apresentou resultado operacional positivo em 2015 e 2016 e, em 2017, o EBITDA tornou-se negativo.

Os dados evidenciam que, mesmo com deficiência em capacidades dinâmicas, a empresa de desempenho inferior conseguia gerar caixa positivo e manter-se com suas diversas lojas ao longo do triênio, mantendo sua liderança de mercado. Mesmo tratando-se de empresa tão longeva, o nível de capacidades dinâmicas é ainda muito baixo. Segundo o conselheiro entrevistado, isso se deve aos concorrentes não se destacarem nessas mesmas capacidades.

A empresa não está sujeita a riscos oriundos do endividamento (ela não possui dívida alguma), o que denota o caráter conservador do CEO, fato destacado pelo conselheiro. Ao mesmo tempo, ainda adota uma prática antiga e arriscada: o uso do crediário próprio por meio de carnê de pagamento.

A empresa ainda realiza planejamento estratégico com o horizonte principal de um ano e não adota - e nem conhece - a maioria das tecnologias disruptivas questionadas ao conselheiro, tais como internet das coisas, bitcoin e blockchain. Conhece apenas o comércio online e o big data, mas não entende ainda como tais tecnologias irão impactar o negócio. Mesmo existindo grandes empresas concorrentes no comércio online, o conselheiro afirma que eles não impactam o mercado da empresa.

No triênio, a principal fonte de riqueza da empresa esteve ligada a seus produtos tradicionais, existentes há mais de 3 anos no seu portfolio e em mercados também já existentes. Não foram criados nesse período novos produtos ou serviços que pudessem agregar valor ao negócio nem prospectados novos mercados além daqueles já conquistados até 2014. Ao mesmo tempo, inovações de processos, tais como esforços para redução de custos, inovações em processos e setores administrativos não foram desenvolvidas no triênio analisado, o que pode decorrer da falta de capacidades dinâmicas diagnosticada no questionário estruturado.

A média de percepção da dinâmica ambiental é baixa (4,25 pontos em 10$)$, mas quando analisada nas categorias que as compõe, percebe-se que a empresa percebeu fortemente a dinâmica do ambiente formado pelos clientes e pelo ambiente econômico (nota 9). A dinâmica do ambiente formado pelos concorrentes foi também percebida (nota 7), principalmente pelo crescimento de concorrentes online (mesmo com a afirmativa do conselheiro de que tal mudança não impactou a empresa). Já a dinâmica dos ambientes regulatório, tecnológico e sociocultural foi percebida como muito baixa, tendendo a estável (nota 1). Já o ambiente formado pelos fornecedores teve dinâmica moderada (nota 5).

Mesmo percebendo nível de dinâmica forte em alguns dos ambientes questionados, tendo sido impactada por variação na taxa de juros e queda no nível de renda da população, a empresa desenvolveu poucas capacidades dinâmicas ao longo do triênio. Apenas a prospecção de novos mercados passou de 'ruim' em 2015-2016 para 'nem boa nem ruim' em 2017 e a reputação no mercado passou de 'ruim' para 'boa' em 2017. A estrutura organizacional da empresa manteve-se constante ao longo do período investigado.

\section{Caso 2: A empresa de Desempenho Superior}

Trata-se de uma empresa do varejo de vestuário que atua há 41 anos na região Sudeste brasileira, vendendo principalmente para as classes C e D. A nota de 1 a 10 para o desempenho geral da empresa foi 9, utilizando-se do mesmo critério para avaliar a empresa de desempenho inferior, o que denota uma empresa de crescimento acelerado e sustentado.

$\mathrm{Na}$ análise de desempenho específico a empresa apresentou, em 2017, EBITDA equivalente à média do setor e crescimento da receita bruta ligeiramente melhor do que a média do setor. Tal realidade, entretanto, é marcada por uma dicotomia setorial: a empresa se localiza no meio de uma faixa muito discrepante de concorrentes que variam de pequenos varejos inexpressivos a grandes varejistas com ações cotadas em bolsa. Encontrar uma referência de avaliação foi difícil para o entrevistado, pois: "se comparar com os pequenos, nosso EBITDA é muito maior, mas com os grandes, estamos dois pontos [percentuais] abaixo do resultado deles".

Já com relação ao endividamento, o conselheiro informou que a empresa esteve fortemente endividada em 2015, fato que começou a ser revertido a partir de 2016 com a contratação de um novo conselheiro especializado em finanças corporativas. Por ser uma empresa que trabalha com algum nível de endividamento, ela também sentiu as variações nas taxas de juros no Brasil.

Antes de 2015, a empresa tinha baixo nível de reputação no mercado, fato que começou a 
mudar a partir de ações definidas pelo conselho para a definição clara de uma proposta de valor que fosse além do preço.

O conselheiro salienta a capacidade executiva dos sócios diretores para implantar as deliberações do conselho. A empresa tem um dos membros da família fundadora como presidente $\mathrm{e}$ seus irmãos participando da diretoria e conselho. $\mathrm{O}$ conselho de administração consultivo foi constituído em 2015 e grandes mudanças foram instaladas desde então. O entrevistado reconhece que a instalação do conselho contribuiu enormemente para a percepção do ambiente externo. Ele afirma que, antes do conselho, a empresa era muito voltada para suas questões internas e tinha grande dificuldade para a tomada de decisão diante da complexidade do ambiente externo. Apesar dos sócios serem avessos ao risco financeiro, não são conservadores para aproveitarem oportunidades. A contratação de "uma consultoria de grande porte acabou com as dúvidas da companhia" e gerou um plano de crescimento acelerado.

Nos anos de 2015-2016, o nível de capacidades dinâmicas da empresa recebeu uma pontuação média de 1,33. Naquela ocasião, a capacidade estratégica da firma era reduzida, com planejamento e execução estratégica percebidos como ruins, assim como sua gestão estratégica de recursos humanos $(\mathrm{RH})$, gestão do conhecimento e inovações em processos administrativos e operacionais. O monitoramento do mercado e a percepção de novas oportunidades foram percebidos como 'nem bom nem ruim', assim como pesquisas de mercado, reputação e prospecção de novos mercados.

Já em 2017, após reestruturação de sua estrutura organizacional, a empresa sofreu um salto significativo nas capacidades dinâmicas, na percepção do entrevistado. O horizonte de visão do planejamento estratégico passou de 1 ano até 2016 para 5 anos em 2017. Mesmo assim, temas atuais como o e-commerce são monitorados sem grandes preocupações, por se considerar que ainda não atrapalham os negócios da empresa ${ }^{5}$.

A média de pontuação das capacidades dinâmicas passou a ser de 2,56, quase o dobro do período anterior, com destaque, agora, para as capacidades estratégicas de percepção e priorização de novas oportunidades, agilidade para a tomada de decisão. Todas as capacidades dinâmicas

5 Durante a entrevista, foi discutido sobre um comportamento de "sapo na panela", o qual foi confirmado pelo entrevistado. Segundo ele, para a maioria das empresas brasileiras, não é vantajoso se adiantar à evolução das tecnologias e do mercado. melhoraram em 2017, com exceção da cooperação e alianças com organizações externas e capacidade de financiamento de inovações, que se mantiveram no mesmo patamar: 'ruim'. Também em 2017, a empresa passou a adotar práticas para o uso de novas tecnologias como big data e inteligência artificial.

A melhoria das capacidades dinâmicas foi significativa em 2017, justamente o período no qual as turbulências de mercado foram reduzidas. O estudo não conseguiu identificar se as crises no período de 2014 foram fundamentais para a criação do conselho ou se o conselho seria criado de qualquer forma.

\section{ANÁLISE COMPARATIVA DOS DOIS CASOS}

Para a análise comparada, medidas objetivas obtidas pelo questionário estruturado foram organizadas em gráficos com dados dispostos lateralmente. Do lado direito dos gráficos, foram registradas as pontuações da empresa de bom desempenho e, do lado esquerdo, a pontuação da empresa de mau desempenho.

O Gráfico 1 demonstra a diferença de desempenho entre as empresas. Em uma escala de 1 a 10 , na qual 1 significava empresa em risco de falência e 10 significava empresa de crescimento acelerado e sustentado, a primeira teve pontuação de 1 e a segunda pontuação de 9 . Esse resultado demonstra o grau de distanciamento entre elas em termos de desempenho, mesmo tratando-se de medidas de percepção.

Já sobre o nível de dinâmica ambiental, a primeira apresentou pontuação média de 4,25 e a segunda, 5,25 (calculadas pela média dos indicadores avaliados). Em uma escala de 1 a 10, na qual 1 significava ambiente estável e 10 significava ambiente totalmente turbulento, mesmo em setores aproximados, há diferença entre a percepção do respondente. O principal fator que contribuiu para a diferença entre essa pontuação foi o nível de dinâmica no ambiente formado pelos fornecedores, conforme será visto com maiores detalhes a seguir.

Já a pontuação geral das capacidades dinâmicas no período 2015-2016 foi muito baixa para ambas as empresas. Em um máximo de 4 pontos, enquanto a empresa de mau desempenho teve nota 1,00 , a empresa de bom desempenho teve nota 1,33 . A percepção melhorou no ano seguinte (para 1,17 e 2,53, respectivamente), demonstrando que as empresas tiveram melhores níveis de capacidades dinâmicas no ano de 2017 do que no biênio 2015-2016. 


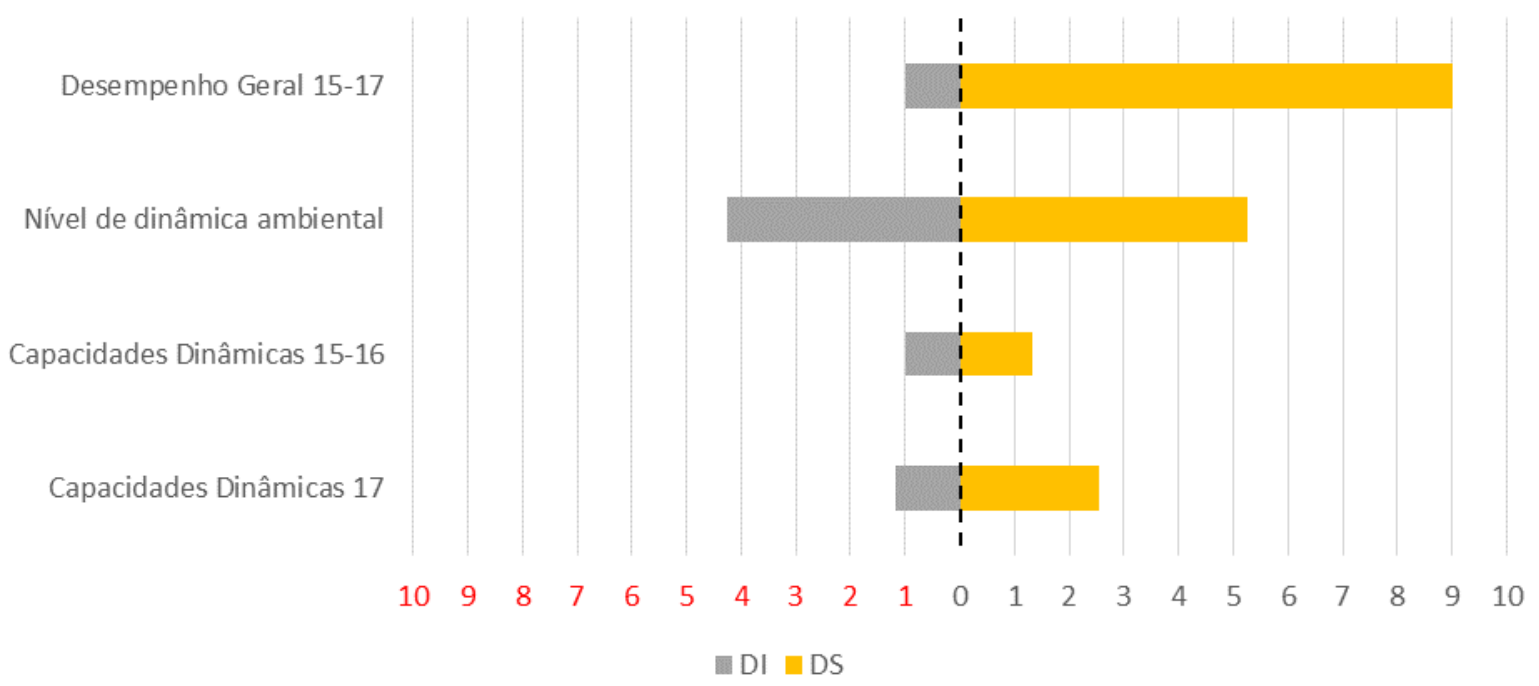

Gráfico 1 - Comparativo consolidado dos elementos investigados nas empresas no triênio 2015-2017

Fonte: dados da pesquisa.

Nota 1: para todos os gráficos apresentados nos resultados, localizam-se à esquerda, em cinza, as notas para a empresa "DI" (empresa de desempenho inferior), e à direita, em amarelo, são apresentadas as notas para a empresa DS (empresa de desempenho superior).

Nota 2: no presente gráfico, apesar da apresentação conjunta para fins de comparação, a escala de capacidades dinâmicas era de 1 a 5 , conforme apresentado na metodologia.

Um maior detalhamento da análise da dinâmica ambiental no triênio 2015-2017 (Gráfico
2) demonstra que para a empresa de bom desempenho, o conselheiro percebe maior nível de dinâmica ambiental principalmente em função da mudança no cenário formado pelos fornecedores e no ambiente regulatório. As mudanças na legislação sobre trabalho escravo impactaram a empresa de bom desempenho por esta possuir atividade produtiva. No caso dos fornecedores, mudanças em função de fornecedores chineses no setor de vestuário fez com que as mudanças nesse cenário fossem mais evidentes para a empresa de bom desempenho.

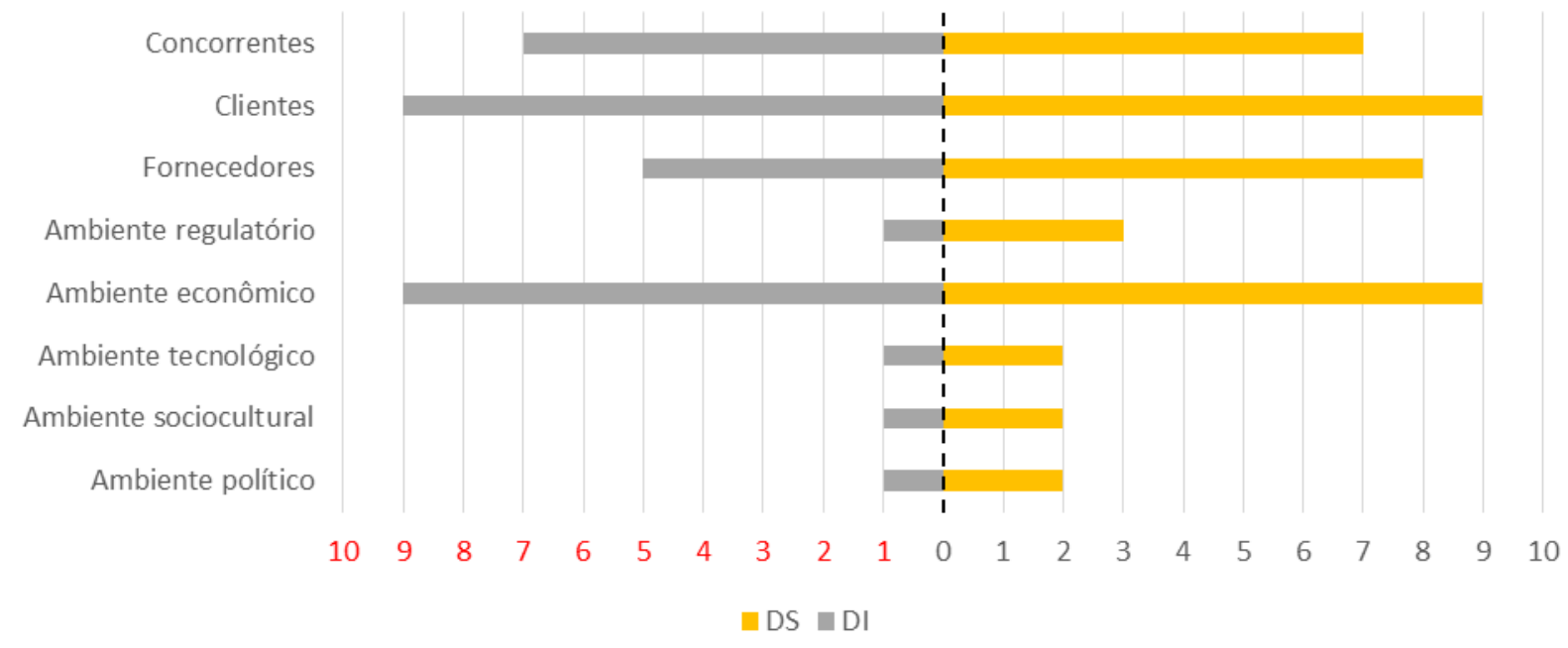

Gráfico 2 - Comparativo da dinâmica ambiental no triênio 2015-2017

Fonte: dados da pesquisa. 
Entretanto, uma segunda análise que tinha o intuito de demonstrar alguns fatores mais detalhados no impacto de eventos externos aos negócios em questão, demonstra riscos de irregularidade dessa medida. O Gráfico 3 demonstra que eventos econômicos como redução de fontes de financiamento e variações cambiais não impactaram a empresa de mau desempenho, entretanto, a pontuação no Gráfico 2 sobre a dinâmica do ambiente econômico foi equivalente.
Variações da taxa de juros

Queda no nível de renda da população brasileira

Variações cambiais

Redução de fontes de financiamento

Produtos ou serviços substitutos

Novas tecnologias

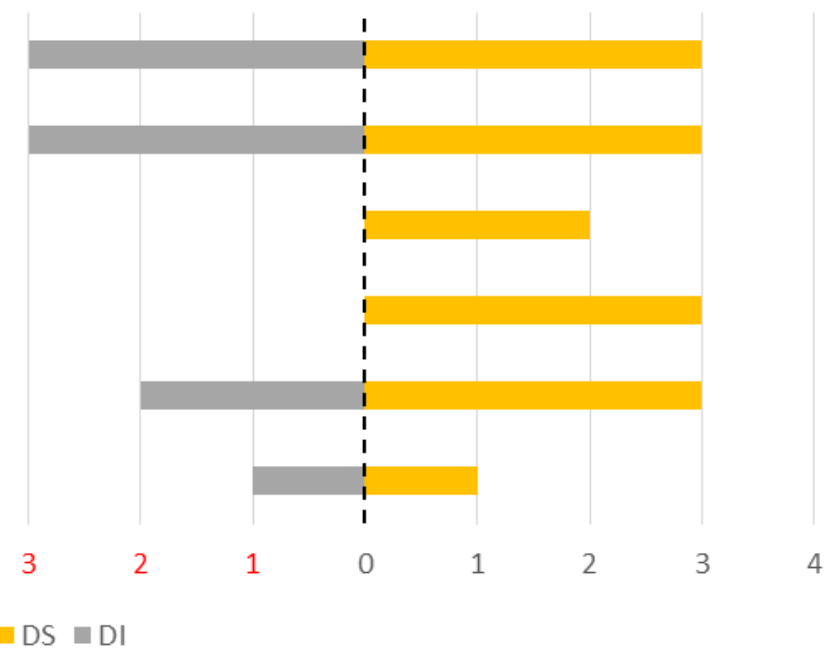

Gráfico 3 - Comparativo do impacto da dinâmica de elementos específicos no triênio 2015-2017

Fonte: dados da pesquisa.

O nível de capacidades dinâmicas foi baixo para ambas as empresas no período de 2015-2016. Entretanto, elas melhoraram significativamente em
2017 na empresa de bom desempenho e muito pouco na empresa de mau desempenho (Gráficos 4 e 5). 
Monitoramento sistematizado do ambiente externo à... Percepção de novas oportunidades e ameaças no.. Priorização das oportunidades e ameaças percebidas Agilidade para a tomada de decisões estratégicas Capacidade analítica de dados para a tomada de decisão...

Pesquisa e desenvolvimento de novos produtos e... Pesquisa de mercado sistematizada Prospecção de novos mercados Reputação no mercado Implantação dos projetos estratégicos Cooperação, alianças e relacionamento estratégico com... Agilidade e acurácia da alta direção na percepção da... Inovação em produtos, serviços ou proposta de valor ao...

Inovação em processos produtivos ou operacionais

Inovação em processos gerenciais e administrativos Capacidade de financiamento de inovações (com capital... Gestão estratégica de Recursos Humanos Gestão do conhecimento sistematizada

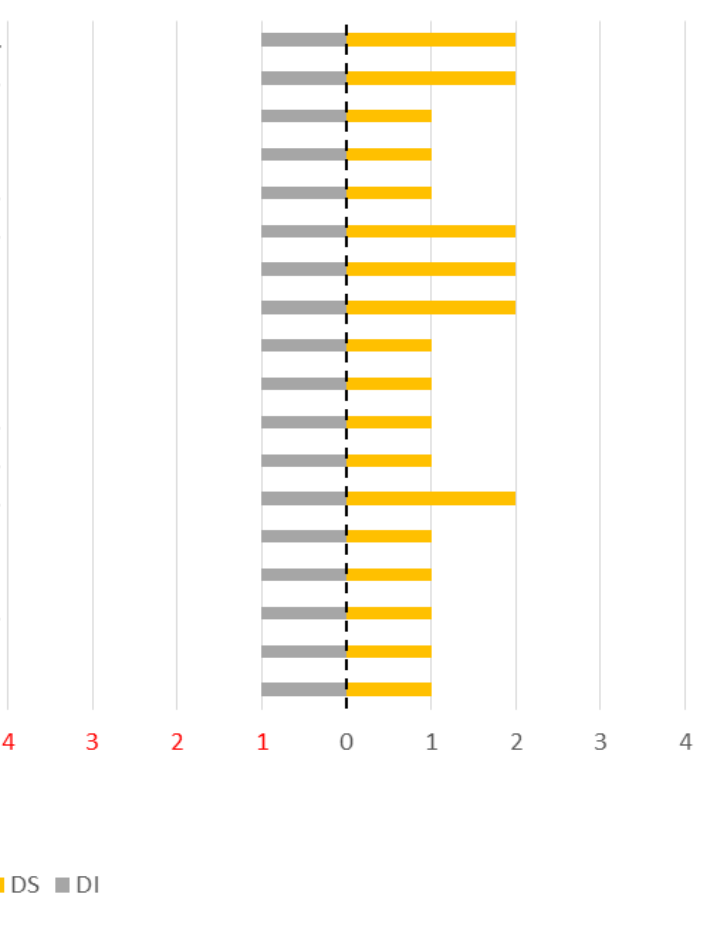

Gráfico 4 - Elementos de capacidades dinâmicas no período 2015-2016 Fonte: dados da pesquisa.

Monitoramento sistematizado do ambiente externo à... Percepção de novas oportunidades e ameaças no... Priorização das oportunidades e ameaças percebidas Agilidade para a tomada de decisões estratégicas Capacidade analítica de dados para a tomada de decisão... Pesquisa e desenvolvimento de novos produtos e... Pesquisa de mercado sistematizada Prospecção de novos mercados Reputação no mercado Implantação dos projetos estratégicos Cooperação, alianças e relacionamento estratégico com... Agilidade e acurácia da alta direção na percepção da... Inovação em produtos, serviços ou proposta de valor ao... Inovação em processos produtivos ou operacionais Inovação em processos gerenciais e administrativos Capacidade de financiamento de inovações (com capital... Gestão estratégica de Recursos Humanos Gestão do conhecimento sistematizada

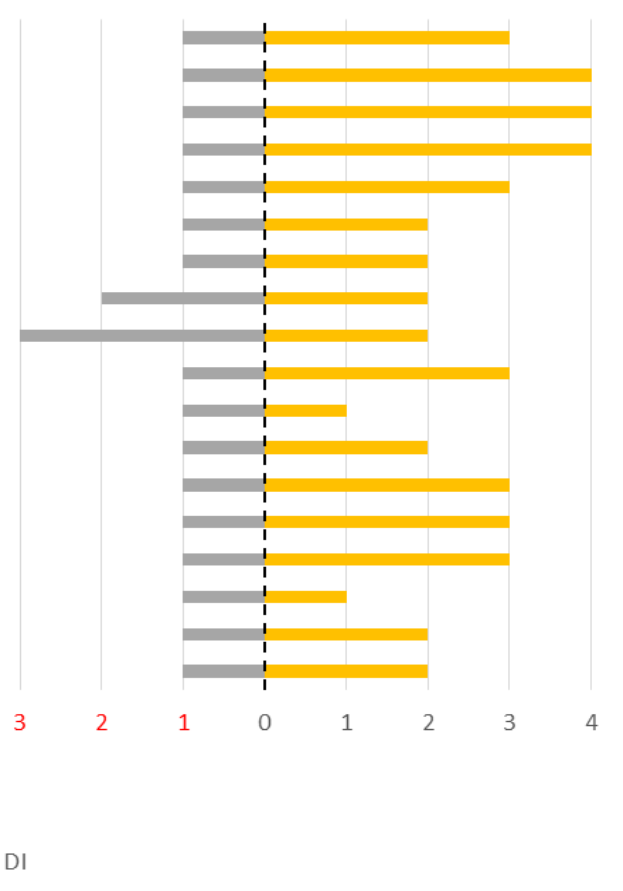

Gráfico 5 - Elementos de capacidades dinâmicas no ano de 2017

Fonte: dados da pesquisa. 


\section{DISCUSSÃO DOS RESULTADOS}

A primeira pergunta que surge diante das teorias analisadas e dos resultados encontrados é acerca dos motivos que fizeram com que empresas com o nível de capacidades dinâmicas tão baixo sobrevivessem - e até mesmo liderassem o mercado - por mais de 40 anos. Afinal, mesmo na empresa de desempenho superior, as capacidades dinâmicas com maior nota não ultrapassaram o nível médio da escala. Pode-se perceber ainda, que algumas das capacidades com maior pontuação - tal como a percepção do mercado - relacionam-se à necessidade que o fator 'moda' imprime aos negócios de vestuário de forma intrínseca e não necessariamente como diferencial estratégico.

Conforme explicado pelo respondente, a capacidade que justificou a sobrevivência da empresa de desempenho inferior foi a gestão intensa e focada no caixa diário, bem como o forte envolvimento do fundador no dia a dia dos negócios. Essa visão de curtíssimo prazo poderia ser considerada no contexto das capacidades ordinárias as quais, conforme citado por Karna, Richter e Riesenkampff (2016) mediam a relação entre capacidades dinâmicas e desempenho e devem ser consideradas para explicação do desempenho.

Mesmo com baixos níveis de capacidades dinâmicas em 2015-2016 - média de 1,33 - a empresa de desempenho superior obteve resultados superiores em 2017. Já a pontuação média das capacidades dinâmicas em 2017 foi de 2,56, muito próxima da média "nem boa nem ruim" prevista no questionário. Tal pontuação pode indicar que tratar conjuntos de capacidades de forma agrupada pode levar a conclusões equivocadas, uma vez que é possível que empresas possam ter desempenho superior sem contar com altos níveis de capacidades dinâmicas específicas, tais como alianças e cooperação e financiamento de inovações nos casos investigados. Mediante afirmativa do entrevistado, as capacidades dinâmicas de percepção e análise do ambiente externo, de implantação de projetos estratégicos e de inovação foram realmente significativas para o desempenho das empresas aqui investigadas.

Mesmo com menor nível de dinâmica ambiental em 2017, as capacidades dinâmicas tiveram um salto na empresa de Desempenho Superior no último ano e melhoria modesta na empresa de Desempenho Inferior. Tal realidade pode estar relacionada a uma distância temporal entre a dinâmica ambiental e o desenvolvimento de capacidades de forma contingencial. Outro fator a se investigar é o tempo de maturação das capacidades dinâmicas e, diante dele, a relevância da distância temporal entre o desenvolvimento das capacidades dinâmicas e o desempenho. $\mathrm{O}$ caso da empresa de desempenho superior indica que o período de 1 ano pode ser suficiente tanto para o desenvolvimento das capacidades estratégicas quanto para a obtenção de desempenho superior, tal como tratado em estudos prévios (Karna et al., 2016).

A empresa de desempenho inferior começou seu processo de desenvolvimento e capacidades pelo mercado (prospecção e reputação), enquanto que a empresa de desempenho superior fortaleceu suas capacidades dinâmicas primeiramente por meio daquelas relacionadas ao planejamento, decisão e implantação estratégica. A partir da entrevista semiestruturada, foi possível também perceber a relevância da governança corporativa em especial a implantação do conselho - para o desenvolvimento das capacidades de ambas as empresas.

Sobre o impacto sofrido pelas empresas em função da dinâmica de elementos específicos do ambiente externo, percebe-se que a empresa de desempenho superior foi mais impactada uma vez que variações cambiais e redução de fontes de financiamento não tiveram qualquer relevância para a empresa de desempenho inferior. Tal resultado parece estar relacionado à gestão mais tradicional e, portanto, menos exposta a riscos - da empresa de desempenho inferior.

Sobre a percepção do grau de dinâmica ambiental, salientou-se o baixo nível de percepção da dinâmica tecnológica, fato que foi confirmado na entrevista semiestruturada pelo baixo nível de conhecimento de alguns elementos tecnológicos em desenvolvimento na atualidade. As empresas parecem, entretanto, estar alheias ao desenvolvimento do e-commerce, diante das afirmativas do respondente de que não se trata de um fator que ameaça de forma relevante tais empresas.

\section{CONCLUSÕES}

O método adotado não permite generalizações ou extrapolações para outras empresas. Entretanto, o caráter exploratório da relação entre capacidades, desempenho e ambiente de crise brasileira permitiu tanto o fortalecimento de propostas teóricas prévias quanto a identificação de pistas novas e abordagens complementares para alimentar estudos futuros acerca das capacidades dinâmicas, inclusive para a criação de escalas de medição. Foi também possível concluir que as 
capacidades dinâmicas são importantes para o desempenho das empresas investigadas, uma vez que algumas delas foram fundamentais para o salto de desempenho da empresa de desempenho superior em 2017 e que serão necessárias para a reversão do resultado da empresa de desempenho inferior.

O baixo nível de capacidades dinâmicas nas empresas longevas estudadas indica três possíveis vias de análise: (1) uma ideia tolerância ambiental, uma vez que o mecanismo de seleção do mercado (Nelson \& Winter, 2005) não exigiu grau de excelência das capacidades aqui avaliadas; (2) a existência de outros tipos de capacidades que tenham sido mais relevantes para a sobrevivência dessas empresas, tais como capacidades ordinárias (Karna et al., 2016) e (3) a irrelevância de algumas capacidades para os setores investigados ${ }^{6}$.

Assim, para a construção de instrumentos de análise e escalas (Hair, Anderson, \& Black, 2005), denota-se a necessidade de se manter clusters de capacidades dinâmicas ou de trata-las de forma específica, uma vez que se tratam de construto multidimensional, mas cujas dimensões podem se adequar mais ou menos para cada setor de empresas.

Ainda que Richard et al. (2009) e Denrell, Fang e Zhao (2013) tenham tratado a relação temporal, cumulativa e concomitante entre capacidades e desempenho, sugere-se aqui maiores investimentos na construção de teorias que expliquem a temporalidade entre dinâmica ambiental, o desenvolvimento de capacidades e o desempenho. Outra hipótese a ser somada nessa construção teórica em estudos futuros é a de que o desempenho passado seja fator mais relevante do que a dinâmica ambiental na decisão de implantação de capacidades dinâmicas, tal como indicado por Mahto e Khanin (2015). Sugere-se, para estudos futuros, adequações metodológicas que propiciem a percepção desta relação, principalmente no sentido de se avaliar se a melhoria ou a piora do desempenho antecede o desenvolvimento de capacidades e se tal mecanismo - endógeno - seria mais forte do que o mecanismo de seleção ambiental de capacidades (Nelson \& Winter, 2005).

Outro fator a se considerar é o risco de uma retração no desenvolvimento das capacidades em épocas de crise mais severa, causando um 'congelamento' de algumas delas diante da aversão ao risco e da necessidade de redução do nível de investimentos. Ainda que as evidencias aqui encontradas não possam contribuir com essa a esta questão, não foram encontrados referenciais teóricos que já tenham iniciado essa linha de pesquisa.

Um outro elemento que parece explicar a contento a história de crescimento das empresas investigadas é a vantagem cumulativa citada por Denrell, Fang e Zhao (2013), uma vez que, ao dominarem novos mercados locais, com novas lojas, as empresas podem obter ganhos de escala, ganhos sobre os fornecedores e aumentar barreiras de entrada (o que justificaria a liderança de mercado da empresa de desempenho inferior).

Ao citar que empresas online de grande porte não impactam o negócio da empresa de desempenho inferior e que grandes varejistas não atrapalham a empresa de desempenho superior, delineia-se uma ideia de encaixe específico de tais negócios dentro de mercados também específicos. Tal posicionamento de encaixe teria permitido que as empresas investigadas ganhassem vantagens cumulativas - dependentes da trajetória (Martins, Kato, Martins, \& Silva, 2014) - que as levaram a situações de domínio e proteção em seus mercados, mas que não garantem a sustentabilidade futura.

O estudo também possibilitou o teste de uma escala para a medição de elementos de capacidades dinâmicas e de uma escala de medição de dinâmica ambiental. Esse desenho possibilitou demonstrar que, mesmo no ambiente de crise política delineada no Brasil, a percepção de mudanças sobre alguns elementos do contexto foi pequena. Nesse sentido, medidas de incerteza se mostraram distintas de medidas de dinâmica, tal como proposto por Teece, Peteraf e Leih (2016) e a ideia de crise pode não estar associada ao dinamismo relevante ao construto das capacidades dinâmicas.

Por fim, o baixo nível de capacidades dinâmicas em empresas tão longevas, permite ainda a consideração de que o paradigma da visão baseada em recursos (Barney, 1991) pode não ser suficiente para explicar o desempenho das empresas investigadas e que uma teoria baseada em capacidades seria mais proveitosa se contemplasse elementos do paradigma estrutura-condutadesempenho (Hoskisson et al., 1999). A relevância de capacidades não dinâmicas, tal como a governança corporativa ainda sugere a importância de um tratamento mais equânime entre capacidades ordinárias e dinâmicas, tal como proposto por Karna, Richter e Riesenkampff (2016).

\footnotetext{
${ }^{6}$ Esta última via de análise deve ser considerada de forma relativa à realidade do contexto, o que contempla também à ideia de tolerância ambiental.
} 


\section{REFERÊNCIAS}

Alerigi, A. (2017, July). Lojas Renner tem alta de $10,7 \%$ no lucro líquido do $2^{\circ}$ tri. Reuters. Retrieved from

https://br.reuters.com/article/businessNews/idBRK BN1AA2OD-OBRBS

Alves, A. C., Barbieux, D., Reichert, F. M., TelloGamarra, J., \& Zawislak, P. A. (2017). Innovation and dynamic capabilities of the firm: defining an assessment model. RAE - Revista de Administração de Empresas, 57(3), 232-244.

Balestro, M. V., Vargas, E. R., \& Machado, E. V. Jr. (2007). Estratégias comparativas em estudos de caso em administração. In Encontro de Ensino e Pesquisa de Administração e Contabilidade (pp. 19).

Barney, J. (1991). Firm resources and sustained competitive advantage. Journal of Management, 17(1), 99-120.

Becker, M. C., \& Knudsen, T. (2005). The role of routines in reducing pervasive uncertainty. Journal of Business Research, 58(6), 746-757.

Bennett, N., \& Lemoine, G. J. (2014). What VUCA really means for you. Harvard Business Review, (JAN-FEB).

Carvalho, L. M. (2017). Atividade econômica: desempenho do PIB. Retrieved February 19, 2018, from

http://www.ipea.gov.br/cartadeconjuntura/index.ph $\mathrm{p} / \mathrm{tag} / \mathrm{crescimento-economico/}$

Cepeda, G., \& Vera, D. (2007). Dynamic capabilities and operational capabilities : A knowledge management perspective, 60, 426-437.

Chan, H. kai, Yee, R. W. Y., Dai, J., \& Lim, M. K. (2016). The moderating effect of environmental dynamism on green product innovation and performance. International Journal of Production Economics, 181, 384-391.

Cleto, P., \& Machado, D. (2015, December 16). Fitch rebaixa rating e Brasil perde grau de investimento. Jornal Valor Econômico. Retrieved from http://www.valor.com.br/financas/4360470/fitchrebaixa-rating-e-brasil-perde-grau-de-investimento\#

Collis, D. J. (1994). Research note: how valuable are organizational capabilities? Strategic Management Journal, 15(1 994), 143-152.

Cornell University, INSEAD, \& WIPO. (2017). The global innovation index 2017: innovation feeding the world. Ithaca, Fontainebleau, Geneva.

Daft, R. L., Sormuren, J., \& Parks, D. (1988). Chief executive scanning, environmental characteristics, and company performance: an empirical study. Strategic Management Journal, 9(2), 123-139.

Denrell, J., Fang, C., \& Zhao, Z. (2013). Inferring superior capabilities from sustained superior performance: a bayesian analysis. Strategic Management JournalStrategic Management Journal, 34, 182-196.

Dess, G. G., \& Beard, D. W. (1984). Dimensions of organizational task environments. Administrative Science Quarterly, 29, 52-73.

Duncan, R. B. (1972). Characteristics of organizational environments and perceived environmental uncertainty. Administrative Science Quarterly, 17(3).

Eisenhardt, K. M., Furr, N. R., \& Bingham, C. B. (2010). CROSSROADS - microfoundations of performance: balancing efficiency and flexibility in dynamic environments. Organization Science, 21(6), 1263-1273.

Eisenhardt, K. M., \& Martin, J. A. (2000). Dynamic capabilities: what are they? Strategic Management Journal, 21(10-11), 1105-1121.

Fainshmidt, S., Nair, A., \& Mallon, M. R. (2017). MNE performance during a crisis : An evolutionary perspective on the role of dynamic managerial capabilities and industry context. International Business Review, 26(6), 1088-1099.

Ferreira, P. C. (2017). Indicador de incerteza da economia Brasil. Rio de Janeiro: Fundação Getúlio Vargas.

Gasparini, C. (2016, May). As 10 áreas com mais demissões até o momento. Você S.A.

Giraud, O. (2009). Comparação dos casos mais contrastantes: método pioneiro central na era da globalização. Sociologias, (22), 54-74.

Hair, J. F. J., Anderson, R. E., \& Black, W. C. (2005). Analise multivariada de dados. Porto 
Alegre: Bookman.

Hermida, X., \& Benites, A. (2017, August 3). Deputados salvam Temer e enterram denúncia de corrupção. El País.

Hoskisson, R. E., Hitt, M. A., Wan, W. P., \& Yiu, D. (1999). Theory and research in strategic management : swings of a pendulum. Journal of Management, 25(3), 417-456.

Instituto Brasileiro de Geografia e Estatística. (2017). PNAD Contínua: taxa de desocupação cai em 11 das 27 UFs no $2^{\circ}$ trimestre de 2017.

Retrieved July 20, 2011, from https://agenciadenoticias.ibge.gov.br/agencianoticias/2013-agencia-de-noticias/releases/15693pnad-continua-taxa-de-desocupacao-cai-em-11-das27-ufs-no-2-trimestre-de-2017.html

Instituto Brasileiro de Geografia e Estatística (2018). PIB avança 1,0\% em 2017 e fecha ano em R\$ 6,6 trilhões. Retrieved August 20, 2007, from https://agenciadenoticias.ibge.gov.br/agencianoticias/2013-agencia-de-noticias/releases/20166pib-avanca-1-0-em-2017-e-fecha-ano-em-r-6-6trilhoes.html

Jansen, J. J. P., Bosch, F. A. J. Van Den, \& Volberda, H. W. (2006). Exploratory innovation, exploitative innovation, and performance : effects of organizational antecedents and environmental moderators. Management Science, 52(December 2017), 1661-1674.

Karna, A., Richter, A., \& Riesenkampff, E. (2016). Revisiting the role of the environment in the capabilities - financial performance relationship : A meta-analysis. Strategic Management Journal, 37, 1154-1173.

King, G., Keohane, R. O., \& Verba, S. (1995). Designing social inquiry - scientific inference in qualitative research. Princeton: Princeton University Press.

Leiblein, M. J. (2011). What do resource- and capability- based theories propose? Journal of Management, 37(4), 909-932.

Li, D. yuan, \& Liu, J. (2014). Dynamic capabilities, environmental dynamism, and competitive advantage: Evidence from China. Journal of Business Research, 67(1), 2793-2799.

Lojas Renner S.A. (2017). Relatório Anual 2016.
Porto Alegre.

Mahto, R. V., \& Khanin, D. (2015). Satisfaction with past financial performance, risk taking, and future performance expectations in the family business. Journal of Small Business Management, 53(3), 801-818.

Makkonen, H., Pohjola, M., Olkkonen, R., \& Koponen, A. (2014). Dynamic capabilities and firm performance in a financial crisis. Journal of Business Research, 67(1), 2707-2719.

Martins, T. S., Kato, H. T., Martins, R. da R. R., \& Silva, E. D. (2014). Um quadro analítico para a tipologia e capacidades dinamicas de Miles e Snow. Revista Ibero-Americana de Estratégia - RIAE, 13(1).

McGahan, A. M. (2004). How industries change. Harvard Business Review, 82(10), 86-94.

Nelson, R. R., \& Winter, S. G. (2005). Uma teoria evolucionária da mudança econômica. Campinas: UNICAMP.

Parnell, J. A., Long, Z., \& Lester, D. (2015). Competitive strategy, capabilities and uncertainty in small and medium sized enterprises (SMEs) in China and the United States. Management Decision, 53.

Paula, L. F., \& Pires, M. (2017). Crise e perspectivas para a economia brasileira. Estudos Avançados, 31(3189), 125-144.

Pereira, H. C. I., Tanure, T., Teixeira, A., \& Missio, F. J. (2017). Uma perspectiva crítica do novo regime fiscal para a dinâmica de curto e longo prazo da economia brasileira. Revista de Economia Do Centro-Oeste, 3(1), 51-69.

Peteraf, M., Di Stefano, G., \& Verona, G. (2013). The elephant in the room of dynamic capabilities: bringing two diverging conversations together. Strategic Management Journal, (34), 1389-1410.

Porter, M. (1986). Estrategia Competitiva. Rio de Janeiro: Editora Campus.

Protogerou, A., Caloghirou, Y., \& Lioukas, S. (2011). Dynamic capabilities and their indirect impact on firm performance. Industrial and Corporate Change, 21(3), 615-647.

Ragin, C. C. (2008). Redesigning social inquiry: 
fuzzy sets and beyond. Chicago: University of Chicago Press.

Ramalho, A. (2017). Taxa de desemprego é de $12,4 \%$ no terceiro trimestre, aponta IBGE. Jornal Valor Econômico, pp. 12-13.

Richard, P. J., Devinney, T. M., Yip, G. S., \& Johnson, G. (2009). Measuring organizational performance: towards methodological best practice. Journal of Management, 35(3), 718-804.

Romme, A. G. L., Zollo, M., \& Berends, P. (2010). Dynamic capabilities, deliberate learning and environmental dynamism : a simulation model. Industrial and Corporate Change, 19(4), 12711299.

Rueda-manzanares, A., \& Arago, J. A. (2008). The influence of stakeholders on the environmental strategy of service firms : the moderating effects of complexity, uncertainty and munificence. British Journal of Management, 19, 185-203.

Schilke, O. (2014). On the contingent value of dynamic capabilities for competitive advantage: the nonlinear moderating efrect of environmental dynamism. Strategic Management Journal, 203(May 2013), 179-203.

Selltiz, C., Jahoda, M., Deutsch, M., \& Cook, S. W. (1967). Research Methods in Social Relations. New York: Holt, Rinehart and Winston.
Sharma, S., Durand, R. M., \& Gur-Arie, O. (1981, August). Identification and analysis of moderator variables. Journal of Marketing Research, 18, 291300 .

Takahashi, A. R. W., Bulgacov, S., Semprebon, E., \& Giacomini, M. M. (2016). Capacidades dinâmicas, capacidade de marketing e desempenho organizacional. Brazilian Business Review, 14(5), 467-478.

Teece, D. J. (2014). The foundations of enterprise performance: dynamic and ordinary capabilities in an (economic) theory of firms. The Academy of Management Perspectives, 28(4), 328-352.

Teece, D. J. (2017). Towards a capability theory of (innovating) firms : implications for management and policy. Cambridge Journal of Economics, 41, 693-720.

Teece, D., Peteraf, M., \& Leih, S. (2016). Dynamic capabilities and organizational agility. California Management Review, 58(4, SI), 13-35.

Teece, D., Pisano, G., \& Shuen, A. (1997). Dynamic capabilities and strategic management. Strategic Management Journal, 18(7), 509-533.

Zahra, S. A., Sapienza, H. J., \& Davidsson, P. (2006, June). Entrepreneurship and dynamic capabilities : a review, model and research agenda. Journal of Management Studies, 43. 